\title{
Delineation of rockburst fractures with ground penetrating radar in the Witwatersrand Basin, South Africa
}

\author{
M. Grodner* \\ CSIR, Division of Mining Technology, PO Box 91230, Auckland Park 2006, South Africa
}

Accepted 17 July 2001

\begin{abstract}
The depth of mining in the gold mines of the Witwatersrand Basin, South Africa is continuously increasing, with several mines already stoping at depths exceeding $3500 \mathrm{~m}$. Due to the high stresses imposed on the rock mass in these deep level mines, a high potential for rockbursts exists. Rockbursts cause injuries and deaths to the workers and lost production time. One of the techniques for reducing the severity of damage of face-bursts (a class of rockbursts where the mining face is ejected into the excavation) is preconditioning. Ground Penetrating Radar (GPR) is used to quantify the change in fracture pattern with preconditioning. It is found that both the intensity and depth to which fracturing occurs ahead of the mining face increased, thereby delineating the area of influence of the preconditioning blast. This allowed the establishment of the optimum preconditioning methodology. To further enhance the understanding of the controlling factors involved, a rockburst was simulated in the tunnel sidewall of a crosscut in a deep level mine. GPR is again used to depict the fracture pattern before and after the synthetic rockburst. The radar scans show a new set of blast-hole parallel fractures, whilst nearer the sidewall, dilation and a slight increase in length of pre-existing fractures occurred. In both cases it is shown that GPR represents a useful tool for rock mechanics practitioners in defining the most suitable strategies for minimizing the damaging effects of rockbursts. (C) 2001 Elsevier Science Ltd. All rights reserved.
\end{abstract}

\section{Introduction}

South Africa's gold mines of the Witwatersrand Basin (Fig. 1) are the deepest excavations in the world, and it is planned to continue mining operations to depths approaching $5000 \mathrm{~m}$ below surface. At these great depths the stresses in the vicinity of the excavation are extremely high. As such the potential for the violent failure of the rock mass is great - these sudden failures are termed rockbursts. When the mining face fails violently, the rockburst is termed a face-burst. Due to the high concentration of personnel at the mining face, for example the drilling crew, this type of rockburst is the most dangerous to workers with even low magnitude events potentially having catastrophic consequences. As such, several research projects aim at the understanding of the mechanisms and reduction of the damage caused by rockbursts. At underground sites (Fig. 1) of two of these projects Ground Penetrating Radar (GPR) has

*Tel.: + 27-11-358-0046; fax: + 27-11-482-1214.

E-mail address: mgrodner@csir.co.za (M. Grodner). been used to examine the fracture pattern in the rock mass around the excavation.

GPR has been used to image the rock mass from underground excavations for more than 40 years, Cook [1] notes that it was first proposed and developed in 1956. Previous workers have noted that GPR has some limitations when used for fracture mapping in a highly stressed underground environment as the target (fractured rock) has a low reflectance because they are closed by the high stresses [2]. In addition there are several undesirable reflectors within the excavation itself, including steel water and air pipes, rail tracks and the adjacent walls of the excavation. As such GPR is best employed as a short-range tool and not for exploration [3].

The first project (Site 1, Fig. 1) aims at reducing the incidence of face bursting in deep stopes and shallower, highly stressed remnant pillars. The latter become "islands" of high stress due to the extensive mining around them. The mining faces of both of these areas are zones of particularly high stress and hence have a greater potential for face bursts. Preconditioning is a technique proven on several deep level mines in South 


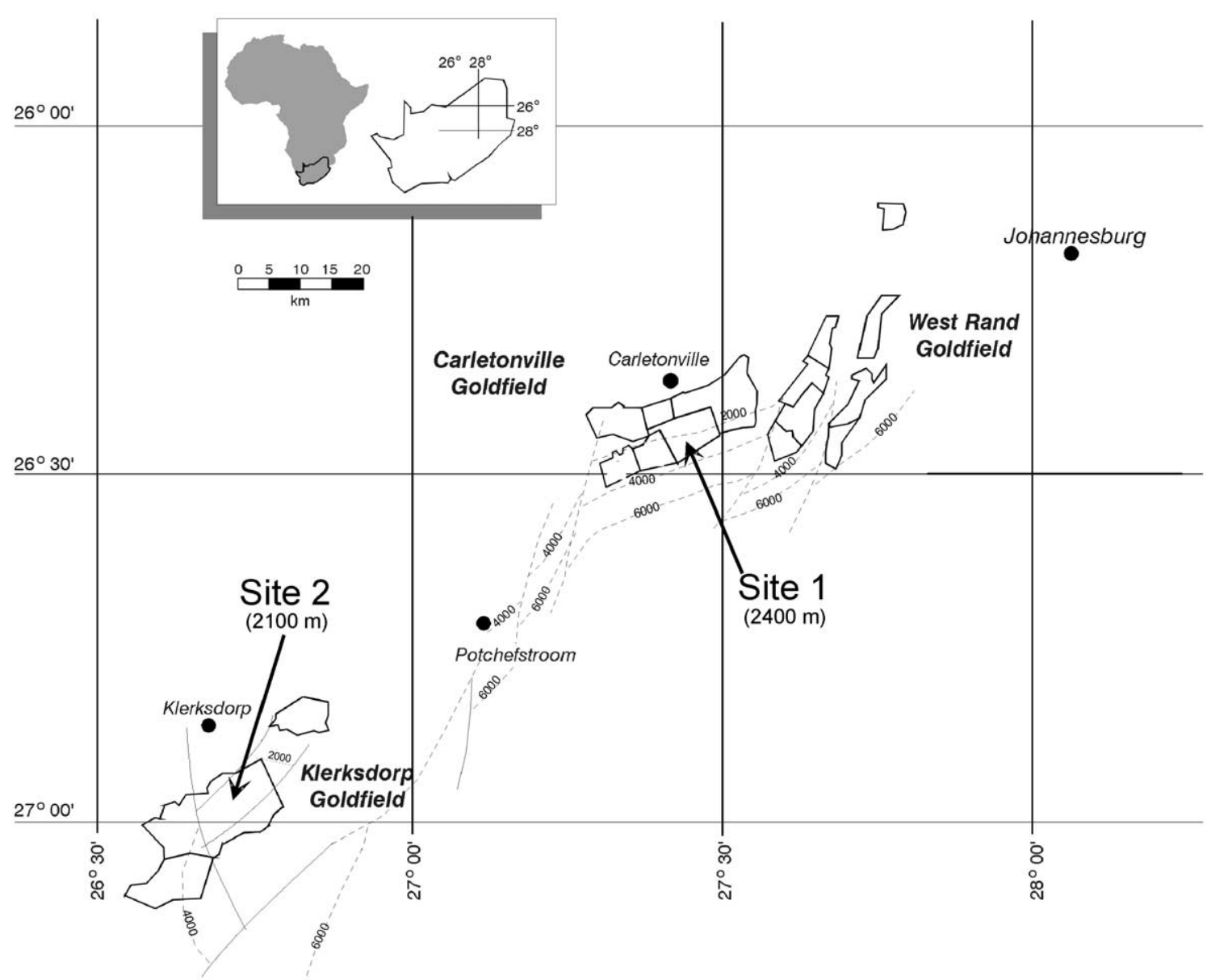

Fig. 1. Plan showing gold mines of the northeastern edge of the Witwatersrand Basin, South Africa. Depth contours of the figure. Rand Group are shown in metres. The positions and depths of the two underground experimental sites where GPR was employed are also indicated (modified after [10] and [11]).

Africa to reduce the incidence of face bursts [4]. This is achieved by detonating explosives in the confined rock mass ahead of the mining face, thereby transferring the stresses further away and effectively de-stressing the immediate face area. There are two methods of preconditioning, namely face parallel and face perpendicular. In the first method, a large diameter $(\sim 50 \mathrm{~mm})$ hole is drilled parallel to the excavation approximately $5 \mathrm{~m}$ ahead of the mining face. This hole is packed with explosives and detonated. Mining then continues up to the position of the preconditioning hole, at which stage another face parallel preconditioning hole is detonated. This type of preconditioning is ideal for the extraction of remnants, such as stabilizing pillars, where there is access to the ground ahead of the stope. The second method of preconditioning is more suited to conventional production stopes where there is no access to the ground ahead. In this method long $(3 \mathrm{~m})$ holes are drilled at the same time as the normal $1-1.2 \mathrm{~m}$ long production holes. The first meter of the hole (closest to the excavation) is stemmed. These preconditioning holes are then detonated at the same time as the normal
Table 1

Number of scans undertaken at various range settings at the two sites

\begin{tabular}{llll}
\hline $\begin{array}{l}\text { Two-way travel } \\
\text { time (ns) }\end{array}$ & $\begin{array}{l}\text { Approximate depth } \\
\text { of penetration }(\mathrm{m})\end{array}$ & \multicolumn{2}{l}{ Number of scans } \\
\cline { 3 - 4 } \cline { 3 - 4 } & & Site 1 & Site 2 \\
\hline 35 & 1.75 & 3 & 0 \\
50 & 2.5 & 7 & 3 \\
70 & 3.5 & 8 & 4 \\
100 & 5.0 & 1 & 2 \\
150 & 8.0 & 6 & 6 \\
\hline
\end{tabular}

production blast, but in a sequence that ensures that there is at least $1 \mathrm{~m}$ of intact rock surrounding the preconditioning hole, immediately prior to its detonation.

The second project also aimed at the alleviation of rockbursts (Site 2, Fig. 1) was a controlled blast experiment. A large quantity of explosives was placed in holes parallel to an abandoned crosscut and detonated to simulate the effects of a seismic event [5]. GPR, fracture mapping and extensometer measurements, as well as detailed seismic monitoring was used to 
examine the changes in the rock mass due to the controlled blast [5].

As the penetration depth of the radar signal is dependent on the transmitted wavelength, there is a loss of detail with increased depth of penetration. To account for this, each survey consisted of several scans at different range settings, or changes in the two-way travel time of the pulse (Table 1). This allowed detailed examination of the fracturing around the preconditioning holes that extended $2-2.5 \mathrm{~m}$ into the face after the production blast.

\section{The effects of preconditioning on the fracture pattern (Site 1)}

Although it was shown that preconditioning did indeed cause a reduction in the incidence of face bursts [6], details of the mechanism by which this occurred were not known. The SIR-2M radar system developed specifically for application in harsh underground conditions by GSSI, in conjunction with the CSIR, was used to aid in the understanding of the mechanisms. A $500 \mathrm{MHz}$ antenna was attached to the system and moved along the face (Fig. 2). The antenna is connected to a toughened data-acquisition unit, with pre-set rangegain This configuration is ideal for underground situations, as the individual components are small enough to be carried through the narrow stopes and the equipment is robust enough to withstand the high temperatures and rough treatment. So as to avoid any interference that the metallic drills and their water pipes might have on the radar signal, surveys of preconditioned and unpreconditioned faces were undertaken before the start of the shift.

The radargrams clearly show the extent and intensity of the fracturing associated with the preconditioning blast. Examples of these are shown in Figs. 3 and 4. It was assumed, during the interpretation of these radargrams that the greater the intensity of fracturing and the higher the dilation on the individual fractures, the stronger the reflection of the electromagnetic pulse would be. The fractures most likely to be detected with GPR are steeply dipping and face parallel in orientation. Fracture mapping indicated that there was a $20 \%$ increase in the number of fractures in this orientation, within the plane of the reef [7]. It is therefore concluded that the stronger electromagnetic reflections seen in the radargrams (Figs. 3 and 4) indicate a greater intensity of fracturing and dilation of individual fractures associated with the preconditioning blast.

The radargrams not only showed increase in number of fractures but also the shape of the fracture envelope. Fig. 3 clearly shows that the area of influence of each preconditioning hole can be defined using the GPR. Of interest also is, that the GPR showed that where the

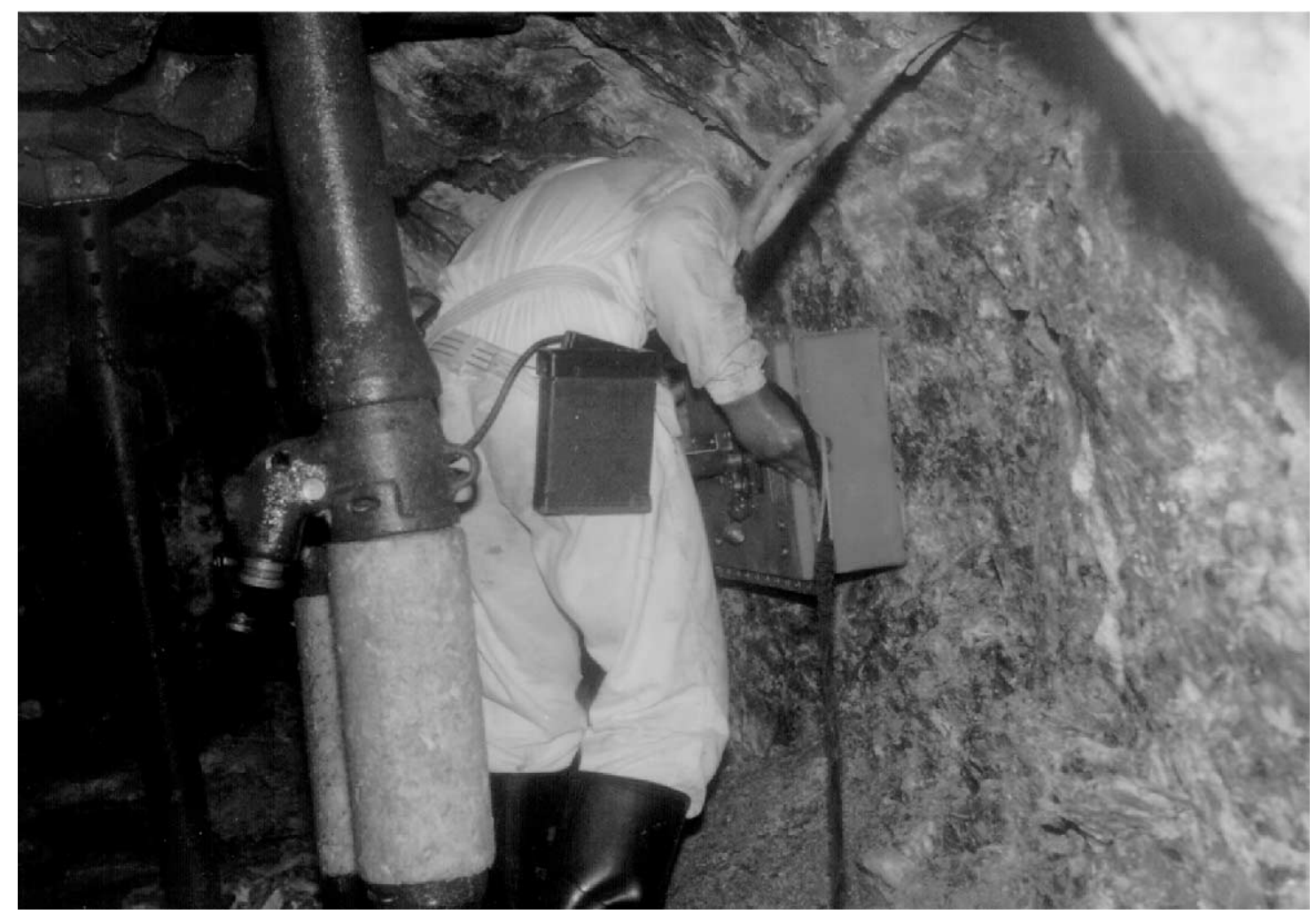

Fig. 2. The SIR-2M GPR system with a $500 \mathrm{MHz}$ antenna being dragged along the face to collect data on the fracturing ahead of mining. 


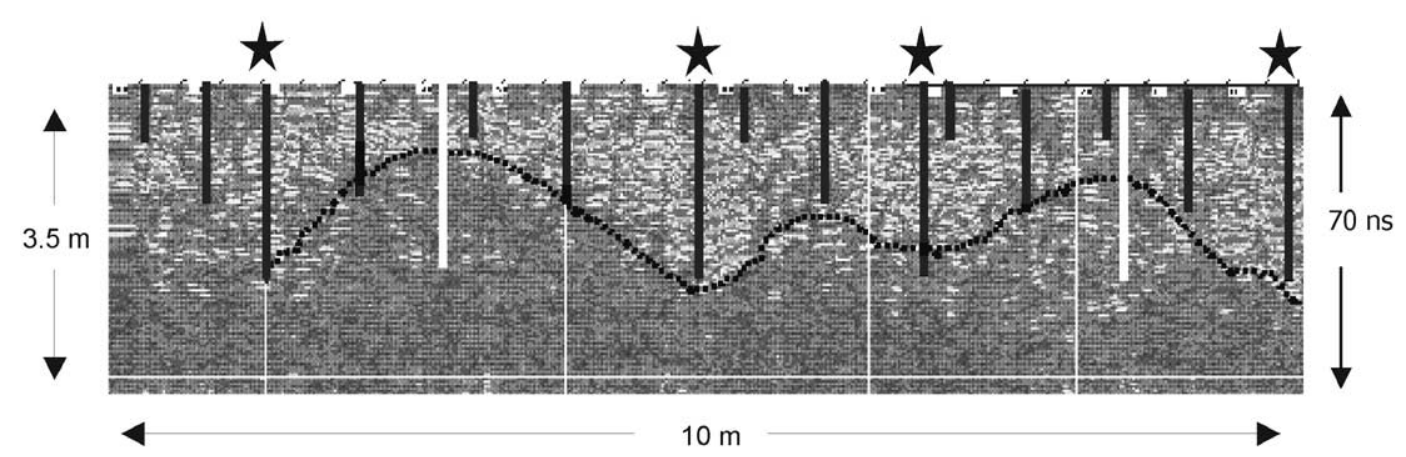

Fig. 3. GPR scan of a preconditioned face. Stars indicate the position of preconditioning holes drilled immediately prior to the scan. The vertical lines indicate the approximate depth of the holes from previous blasts (taking into account a $1 \mathrm{~m}$ face advance per blast). No preconditioning holes were drilled in the position of the two light lines - note how the fracturing does not extend around these positions.

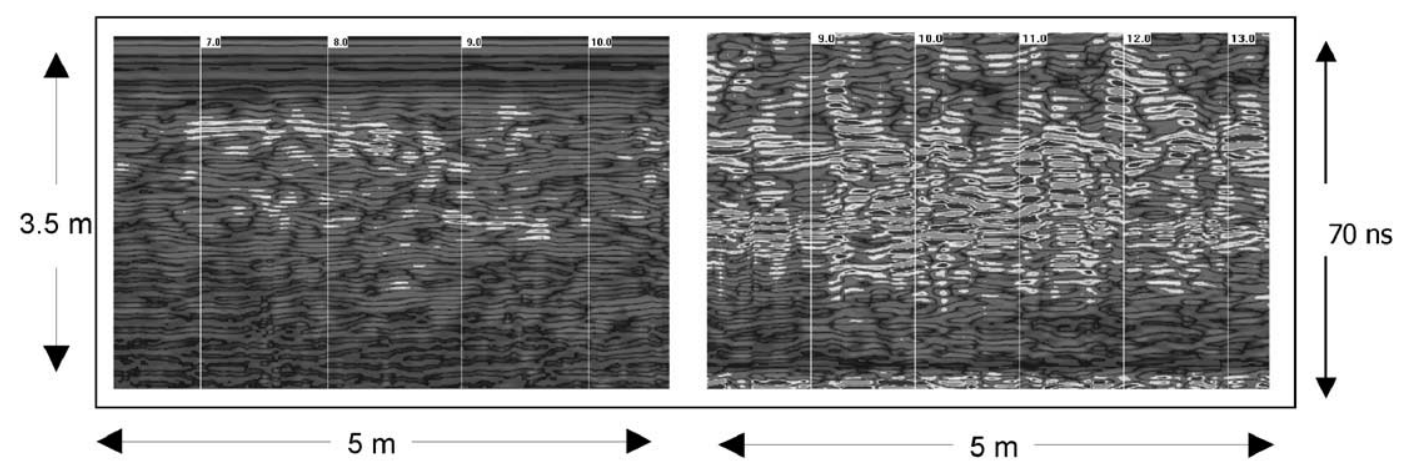

Fig. 4. GPR scans of unpreconditioned (left) and preconditioned (right) faces. Note both the increases in depth and intensity of the fracturing in the preconditioned face.

preconditioning blast holes had not been drilled the fracturing does not extend into the rock mass. Fig. 3 also shows that when the holes are closer than $2.5 \mathrm{~m}$, there is a development of a more continuous fracture zone deeper into the rock mass ahead of the stope face. It was proposed that preconditioning would increase the zone of fracturing and that this serves as a cushion, absorbing the seismic energy and thus preventing a face burst [8]. The GPR data not only confirms this hypothesis, by showing that there is in fact an increase in the fracturing ahead of the face, but can also be used to determine the optimal spacing of $2.5 \mathrm{~m}$ for the preconditioning holes. If the holes were further apart, fractures from adjacent holes would not interconnect.

\section{The fracture pattern of a simulated rockburst (Site 2)}

An attempt was made to simulate the effects of a rockburst due to a seismic event by means of a large detonation in solid rock $5 \mathrm{~m}$ into a tunnel sidewall [5]. The scans produced by the GPR were used to delineate the fracture pattern existing in the area prior to and after the simulated rockburst. It was anticipated that the GPR would at least qualitatively show the change in the fracturing around the area of the blast holes and in the vicinity of the tunnel wall.
The same radar system configuration as used at Site 1 was employed here. Table 1 shows the various ranges scanned. Rock-bolts in the tunnel sidewall will interfere with the scans, as they are strong electromagnetic reflectors. It was however possible, in most cases, to avoid the bolts during the scan. Even when the antenna was dragged across the bolts, there was very little interference, because of the small cross-sectional area of the bolt that was exposed to the radar signal. The steel pipes that were placed in the tunnel to anchor the drill machine would interfere with the radar signal, but the radar signature from the pipes are easily recognised and thus ignored on the radargram during interpretation.

Initially eight GPR scans were taken along a $22 \mathrm{~m}$ long section of the tunnel, with the projected area of the blast being in the centre of this section. Four scans were taken in either direction to see if there was any difference in the signal when the radar system was initialised at different ends of the scan. It was found that there was very little difference in the processed radargrams. A well-defined band of reflections from approximately $0.5 \mathrm{~m}$ into the sidewall to a depth of about $4.5 \mathrm{~m}$ is apparent in the scan (Fig. 5a). These have been interpreted as the mining induced fractures that formed during the development of the tunnel.

Seven GPR scans were taken after the blast. Due to the fact that there were no major differences in the scans 


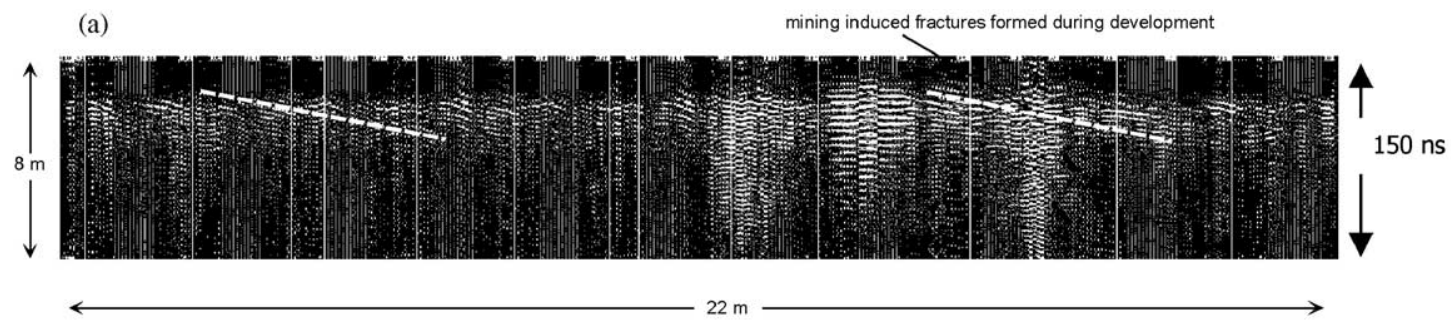

(b)

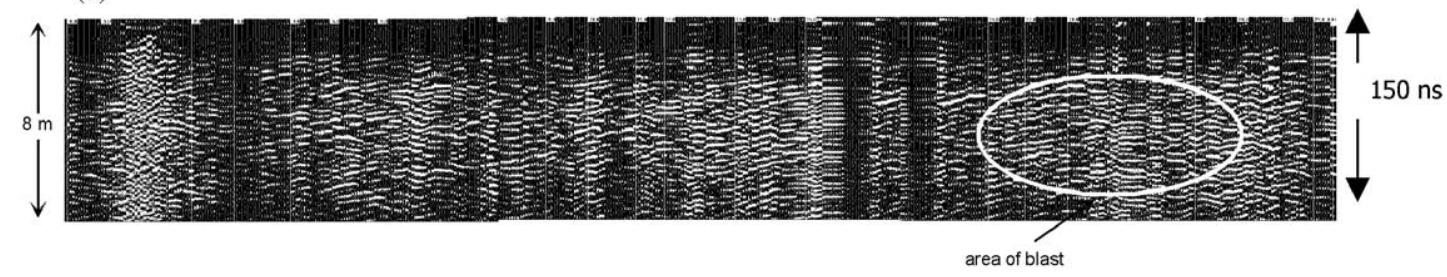

Fig. 5. (a) and (b) Comparison of radar scans from pre- and post-blast. Note the increased amount of reflections in (b)

taken in either direction before the blast, it was decided to do all the scans in the same direction. As the paintmarks from the previous survey were still visible in places, it was possible to repeat the scans over the same area. It was thus possible to directly compare the two sets of results. The quality of the data in the post-blast scans is not as good as that of the pre-blast scans, probably due to poor coupling with the rougher sidewall. This poor coupling was most likely due to the extensive damage caused to the tunnel sidewall by the controlled blast.

The mining induced blast fractures can be seen on both the pre- and post-blast scans (Figs. 5a and b). In the post-blast scan (Fig. 5b) there is an increase in the overall intensity of the reflections near the surface. This is probably due to a combination of two factors. Firstly the gain, which is set automatically by the SIR-2M radar system, was higher for the post blast scans and secondly due to a real increase in the amount of fracturing.

Borehole petroscope work confirmed an increase in the number of fractures that intersected a borehole drilled into the tunnel sidewall [5]. Two possible mechanisms have been suggested: namely the development of new fractures and or the extension of those preexisting [5]. In addition to the increased amount of fracturing near the skin of the excavation there are also several well-defined reflectors at the approximate depth of the blast holes which do not appear on the before blast scans (Fig. 6). These appear to be new fractures interconnecting the blast holes, formed as a result of the controlled blast.

\section{Summary and discussion}

Underground conditions in South Africa's deep level gold mines are not ideal for geophysical studies. The temperatures and humidity are high (greater than $30^{\circ} \mathrm{C}$ and $100 \%$ relative humidity), the available space is often limited (generally $1 \mathrm{~m}$ high excavations) and the presence of support elements such as rock bolts as well as the mine infrastructure (including ventilation pipes and rails) can cause interference with electromagnetic techniques. This study has shown that despite all these obstacles, GPR is a very useful short-range investigative tool for studying the nature of the rock mass surrounding an excavation. It can be effectively used in the determination of the effect of fracturing on the potential damage due to rockbursts.

GPR was used to confirm the hypotheses on the change in the fracturing ahead of the stope with preconditioning and delineate the zone of influence of each preconditioning hole. This allowed the design of a preconditioning methodology that has lead to a major reduction in the incidence of face bursts, when correctly applied [8]. In the controlled blast experiment, GPR showed that the amount of dilation on the mining induced fractures, closer to the excavation, was increased by the blast, whilst at depth it appears as though several tunnel sidewall parallel fractures developed in the vicinity of the blast. It was thus possible to examine the character of the rock mass and determine how it is affected by preconditioning and how it might respond to a seismic event.

The ground conditions and hence the potential applicability of GPR are different in deep level mines, when compared to shallower excavations and conventional surface GPR. In the latter two, the presence of clay and interstitial water results in the strong attenuation of the radar signal [9]. However, the voids or fractures present at shallower depths are also often filled with water, which provides an excellent reflector for the radar pulse. Earlier studies into GPR were aimed at gaining the maximum exploration distance for the radar pulse and encountered problems with the moisture content of the relatively shallow excavations, which limited the probing distance [1]. In contrast to this, the 


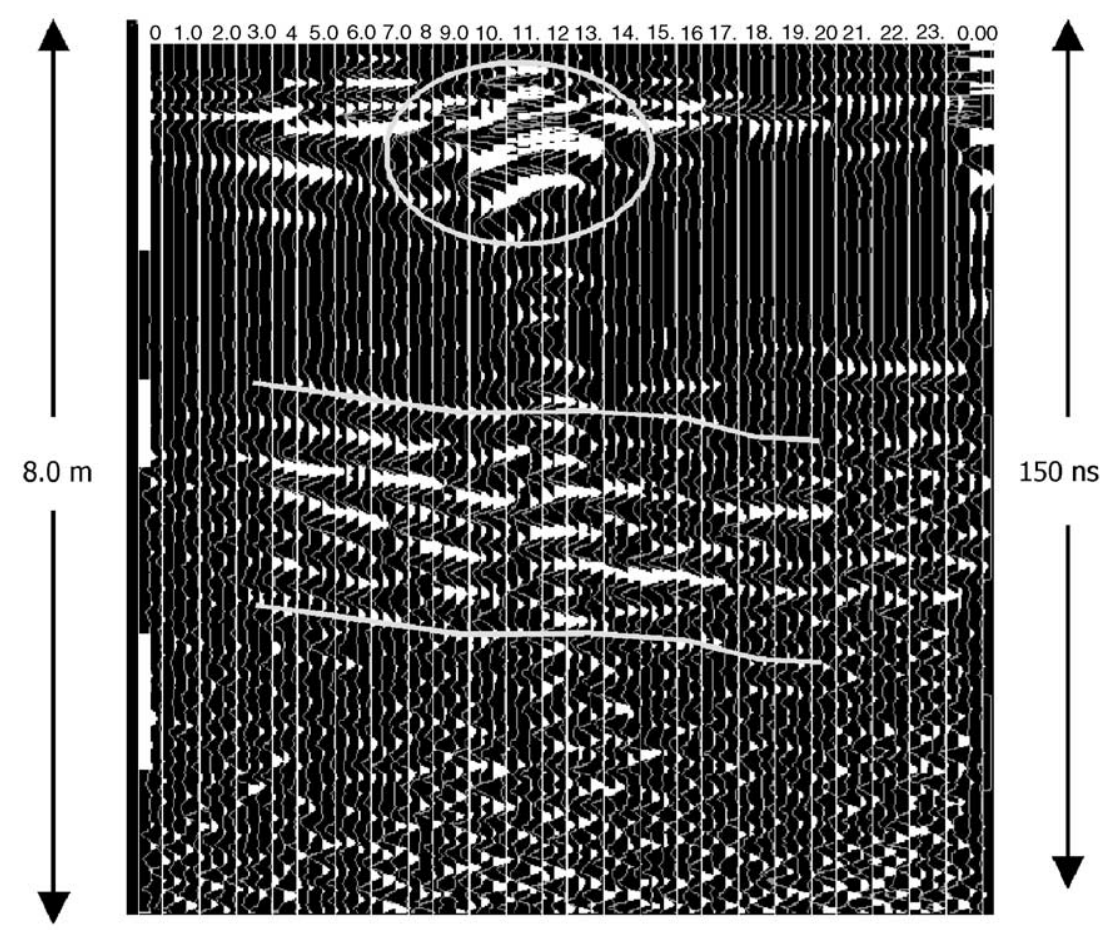

Fig. 6. Scan of tunnel sidewall after the controlled blast, showing the increase in fracturing around the area of the blast (circle) and the development of deeper fractures (parallel lines) at the position of the blast holes.

rock mass conditions investigated during the experiments presented in this paper are essentially dry and have very low clay content, being greenschist-facies metamorphosed, arenaceous-quartzites. In addition there are very few water filled voids present as targets.

The studies described in this paper have shown that GPR can

(a) map the fracture density and pattern around deep excavations,

(b) be used to identify differences in the fracture pattern ahead of mining (e.g. with preconditioning) and

(c) delineate new fractures associated with synthetic rockbursts.

The information acquired using the GPR allowed the optimisation of the preconditioning method and defined the changes in the fracture pattern in the controlled blast experiment. It is suggested that GPR thus represents a very useful tool for determining the rock mass behaviour around excavations. This increased understanding of rockbursts, allows the rock mechanics practitioner to better design strategies for the alleviation of rockbursts.

\section{Acknowledgements}

The Safety in Mines Research Advisory Committee (SIMRAC) is thanked for permission to publish. All the persons involved in the research projects are thanked for their help with both data acquisition, especially A Janse Van Rensburg, and its subsequent interpretation. Dr JK Schweitzer, Dr GR Olhoeft and an anonymous reviewer are thanked for their constructive and insightful reviews of this paper.

\section{References}

[1] Cook JC. Radar transparencies of mine and tunnel rocks. Geophysics 1975;40:865-85.

[2] Moymayaz M, Hara,A, Hassini, FP, Sandri I. Application of GPR for a more efficient mine planning. GPR 94, Proceedings of the Fifth International Conference on Ground Penetrating Radar. Kitchener, Ontario, Canada 1994. p. 883-94.

[3] Raadsma JM. Ground Penetrating Radar Applications on high grade gold deposits at the Sixteen to One Mine, California. GPR 94, Proceedings of the Fifth International Conference on Ground Penetrating Radar, Kitchener, Ontario, Canada 1994. p. 925-40.

[4] Lightfoot N Kullmann DH, Toper AZ, Stewart RD, Grodner M, Janse Van Rensburg AL, Longmore PJ. Preconditioning to reduce the incidence of face bursts in highly stressed faces. SIMRAC Final Project Report GAP 030. South Africa, Pretoria: Department of Minerals and Energy, 1996. p. 147.

[5] Hagan TO, Milev AM, Spottiswood SM, Vakalisa B, Reddy N. Improvement of worker safety through the investigation of the site response to rockbursts. SIMRAC Final Project Report GAP 530. South Africa, Pretoria: Department of Minerals and Energy, 1998.

[6] Kullmann D, Stewart RD, Lightfoot N, Longmore P. Interim report on the progress towards the implementation of preconditioning as a technique for controlling face-bursting on deep level mines. SIMRAC Interim Project Report GAP 030. South Africa, Pretoria: Department of Minerals and Energy, 1995. 165 pp. 
[7] Grodner M. Fracturing around a preconditioned deep level gold mine stope. Geotech Geol Eng 1999;17:291-304.

[8] Lightfoot N, Kullman D, Leach AR. A conceptual model of a hardrock, deep level tabular ore body that incorporates the potential for face bursting as a natural product of mining. First North American Rock Mechanics Symposium. Rock Mechanics Models and Measurements Challenges From Industry, 1994. p. 903-10.

[9] Knoll MD, Knight R, Relationships between dielectric and hydrogeologic properties of sand-clay mixtures. GPR 94.
Proceedings of the Fifth International Conference on Ground Penetrating Radar, Kitchener, Ontario, Canada, 1994. p. 45-61.

[10] Roberts MCK, Schweitzer JK, Geotechnical areas associated with the Ventersdorp Contact Reef, Witwatersrand Basin, South Africa. J S Afr Inst Mining Metal 1999;157-66.

[11] Pretorius DA, The Witwatersrand Basin surface and subsurface geology and structure. In: Anhaeusser C, Maske S, editors. Mineral Deposits of Southern Africa, vol 1. Johannesburg: The Geological Society of South Africa, 1984. p. 1019. 